\title{
The Response of Selected Terrestrial Organisms to the Martian Environment: A Modeling Study
}

\author{
W. R. KUHN \\ Department of Atmospheric and Oceanic Science, University of Michigan, \\ Ann Arbor, Michigan 48109
}

S. R. ROGERS

Sloan Kettering Institute, New York City, New York 10021

AND

R. D. MacELROY

Extraterrestrial Research Division, NASA, Ames Research Center, Moffett Field, California 94035

Received January 10, 1977 ; revised April 3, 1978

\begin{abstract}
An energy balance model has been developed to investigate how the Martian atmospheric environment could influence a community of photosynthetic microorganisms with properties similar to those of a cyanophyte (blue-green algal mat) and a lichen. Surface moisture and soil nutrients are assumed to be available. The model was developed to approximate equatorial equinox conditions and includes parameters for solar and thermal radiation, convective and conductive energy transport, and evaporative cooling. Calculations include the diurnal variation of organism temperature and transpiration and photosynthetic rates. The influences of different wind speeds and organism size and resistivity are also studied. The temperature of organisms in mats less than a few millimeters thick will not differ from the ground temperature by more than $10^{\circ} \mathrm{K}$. Water loss is actually retarded at higher wind speeds, since the organism temperature is lowered, thus reducing the saturation vapor pressure. Typical photosynthetic rates lead to the production of $10^{-6}$ to $10^{-7}$ mole $\mathrm{O}_{2} \mathrm{~cm}^{-2} \mathrm{day}^{-1}$.
\end{abstract}

\section{INTRODUCTION}

Although experimental studies have examined the possibility of terrestrial organisms (primarily bacteria and fungi) surviving on Mars, the environmental parameters considered have generally been limited to temperature and nutrients. However, photosynthetic organisms, in contrast to heterotrophs, would require exposure to the sun and therefore to the atmosphere. Surface wind, radiation, temperature, water vapor, and carbon dioxide gradients thus become very important factors in metabolic activity. While experiments which include all these factors would be extremely difficult to do, it is relatively easy to model such a system mathematically. Studies of this kind may provide insight into the physical processes coupling the organism to its environment, and may also guide future laboratory studies, eventually allowing the model to be used for predictive purposes.

We modeled two hypothetical communi- 
ties of photosynthetic organisms. Although no terrestrial photosynthetic organisms meet all the requirements for existence on the Martian surface, two which seem to meet some of the conditions are blue-green algae and lichens; we use data for these organisms to illustrate the method. Bluegreen algae can exist in an anaerobic environment such as that found on Mars and withstand extreme temperature variations (Cameron, 1963; Lund, 1962) and desiccation (Cameron, 1963); however, prolonged direct exposure to ultraviolet radiation would be lethal. For this reason, we assume that a layer of dead desiccated cells would develop over a cortex of active cells. In an analogous model, Sagan and Pollack (1974) have suggested that photosynthetic organisms could reside below the surface, with the epilith providing a barrier to ultraviolet radiation. Blue-greens require water activities greater than about 0.9 and while there may be localized regions or pockets of liquid water available, this will certainly not be true over most of the planet. Lichens can withstand extreme desiccation (Rao and Le Blanc, 1966; Kappen, 1973), low temperatures (Kappen, 1973), and high levels of ultraviolet radiation (Siegel and Daly, 1968); some species develop a thickened upper layer after exposure to intense visible and ultraviolet radiation (Siegel and Daly, 1968). Unfortunately, there are no known fungi (and thus presumably lichens) that are anaerobic. The biological parameters and specific values we chose to use in the two models are given in a later section.

Since we are primarily concerned with the interaction of a community of microorganisms with the atmosphere, mass transfer is considered only with regard to its effect on transpiration and photosynthesis. We assume that a nutrient supply and adequate water are available from the subsurface; Mars contains carbon and some hydrogen and oxygen and recently the Viking mission demonstrated that some of the macronutrients, sulphur, iron, and possibly phosphorous are present (Toulmin et al., 1976). Water ice is known to be present in the polar regions (Metz, 1976), and thus might also be stored in the regolith in the form of ice or permafrost.

The temperature of the colony is estimated from an energy model which includes solar and atmospheric radiation, evaporative heat loss, and conductive and convective heat exchange. The rate of photosynthesis is determined from the calculated temperatures and rates of water loss.

\section{METHODOLOGY}

The temperature of the colony $T$ can be calculated from an energy equation

$$
\begin{aligned}
Q_{\mathrm{s}}+Q_{\mathrm{a}}+ & k_{\mathrm{d}}\left(T_{\mathrm{g}}-T\right) / \Delta \\
=\sigma T^{4} & +k_{\mathrm{c}}\left(T-T_{\mathrm{a}}\right) \\
& +L_{\mathrm{s}} d_{0} /\left(r_{0}+r_{\mathrm{a}}\right)
\end{aligned}
$$

where $Q_{\mathrm{s}}$ and $Q_{\mathrm{a}}$ are the solar and atmospheric radiation absorbed by the colony and $\sigma T^{4}$ is the thermal radiation emitted. The colony also exchanges energy with the surface by conduction, represented by the third term: $k_{\mathrm{d}}$ is the thermal conductivity of the organism, $\Delta$ is the thickness of the conducting layer, in this case half the thickness of the organism, and $T_{\mathrm{g}}$ is the ground temperature. Convective transport with the atmosphere is represented by the fifth term where the convection coefficient is $k_{\mathrm{e}}=K / \delta$ with $K$ the thermal conductivity of air and $\delta$ the air boundarylayer thickness. Evaporative cooling is expressed as the sixth term, $L$ is the latent heat of sublimation or condensation, ${ }_{s} d_{0}$ is a temperature-dependent saturation density of water vapor at the colony temperature, $r_{0}$ is the resistance of the colony to water vapor loss, and $r_{\mathrm{a}}=\delta / D$, the resistance of the air boundary layer of thickness $\delta$ and molecular diffusion $D$. 
Both $r_{\mathrm{a}}$ and $k_{\mathrm{c}}$ depend on wind speed $V$ since the boundary-layer thickness is given by $\delta=C\left(L^{\prime} / V\right)^{\frac{1}{2}}$, where $L^{\prime}$ is a characteristic organism size and $C$ is a coefficient which we estimate from the Nusselt number to be approximately 3.4. For a general discussion of the energy balance method in the modeling of organisms, see, e.g., Gates (1968) and Monteith (1973).

Equation (1) is solved for the colony temperature by Newton's iteration method with a convergence criterion of $0.1^{\circ} \mathrm{K}$. Once the temperature is determined, the transpiration rate $W$ is given by

$$
W={ }_{\mathrm{s}} d_{0} /\left(r_{0}+r_{\mathrm{a}}\right) .
$$

The rate of photosynthesis for Model I is represented by

$$
P=P_{m} /\left[1+\left(k_{1} / c\right)\right]\left[1+\left(k_{2} / I\right)\right],
$$

where $c$ is the $\mathrm{CO}_{2}$ concentration in the cell and can be expressed as, $c=c_{\mathrm{a}}-r^{\prime} P$, where $c_{\mathrm{a}}$ is the $\mathrm{CO}_{2}$ concentration in air and $r^{\prime}$ is the total resistance pathway to $\mathrm{CO}_{2}$ diffusion from the air boundary layer to the photosynthetic region in the cell. The term $P_{m}$ is the rate of photosynthesis at saturation levels of $\mathrm{CO}_{2}$ and light intensity $I$. Its variation with temperature is excluded since the Martian temperature range over which photosynthesis can occur is small. The terms $k_{1}$ and $k_{2}$ are the cellular concentrations of $\mathrm{CO}_{2}$ and light intensity, respectively, when photosynthesis is at one-half its maximum value. The second model includes in the denominator $\left[1+\left(k_{3} / S\right)\right]$ to take into account the influence of water loss on photosynthesis. The term $k_{3}$ is defined in analogous fashion to $k_{1}$ and $k_{2}$, and $S$ is the amount of water in the organism expressed as a percentage of its dry weight. Note that (3) depends explicitly on wind speed through the air boundary-layer thickness, which appears as part of $r^{\prime}$, and implicity on temperature, which affects water loss and thus saturation.
TABLE I

Martian Environmental Parameters

\begin{tabular}{cccc}
\hline $\begin{array}{c}\text { Local } \\
\text { time }\end{array}$ & $\begin{array}{c}\text { Solar } \\
\text { radiation } \\
\left(\text { ly min }^{-1}\right)\end{array}$ & $\begin{array}{c}\text { Air } \\
\text { tempera- } \\
\text { ture } \\
\left({ }^{\circ} \mathrm{K}\right)\end{array}$ & $\begin{array}{c}\text { Surface } \\
\text { tempera- } \\
\text { ture } \\
\left({ }^{\circ} \mathrm{K}\right)\end{array}$ \\
\hline 0600 & 0 & 160 & 160 \\
0700 & 0.22 & 170 & 175 \\
0800 & 0.43 & 187 & 196 \\
0900 & 0.61 & 202 & 245 \\
1000 & 0.74 & 217 & 275 \\
1100 & 0.83 & 224 & 283 \\
1200 & 0.86 & 230 & 300 \\
1300 & 0.83 & 232 & 298 \\
1400 & 0.74 & 234 & 297 \\
1500 & 0.61 & 236 & 283 \\
1600 & 0.43 & 238 & 273 \\
1700 & 0.22 & 227 & 247 \\
1800 & 0 & 210 & 215 \\
\hline
\end{tabular}

MODEL (MARTIAN ENVIRONMENT AND ORGANISM)

The relevant parameters chosen for Mars are shown in Table I. The solar radiation and surface and air temperatures correspond to conditions near the equator during equinox. The Martian solar constant is about $0.86 \mathrm{ly} / \mathrm{min}$ and for equinox conditions the diurnal variation of solar radiation is $0.86 \cos h$, where $h$ is the local hour angle; we assume there is no attenuation of the radiation as it passes through the atmosphere. The air and ground temperatures are from the theoretical models of Gierasch and Goody (1968) whose results agree well with the Mariner 6 and 7 data. The Mariner 9 data give somewhat lower ground temperatures, as much as $10^{\circ} \mathrm{K}$. Viking 1 recorded an air temperature about $242^{\circ} \mathrm{K}$ at $1500 \mathrm{hr}$ local time (Hess et al., 1976), which agrees well with the model. Any uncertainty in the temperature model is less than that introduced by our hypothetical organism parameters. We assumed wind speeds ranging from $1 \mathrm{~cm} \mathrm{sec}{ }^{-1}$, representing a sheltered environment, to $10 \mathrm{~m} \mathrm{sec} \mathrm{se}^{-1}$, representing full exposure to the wind. 


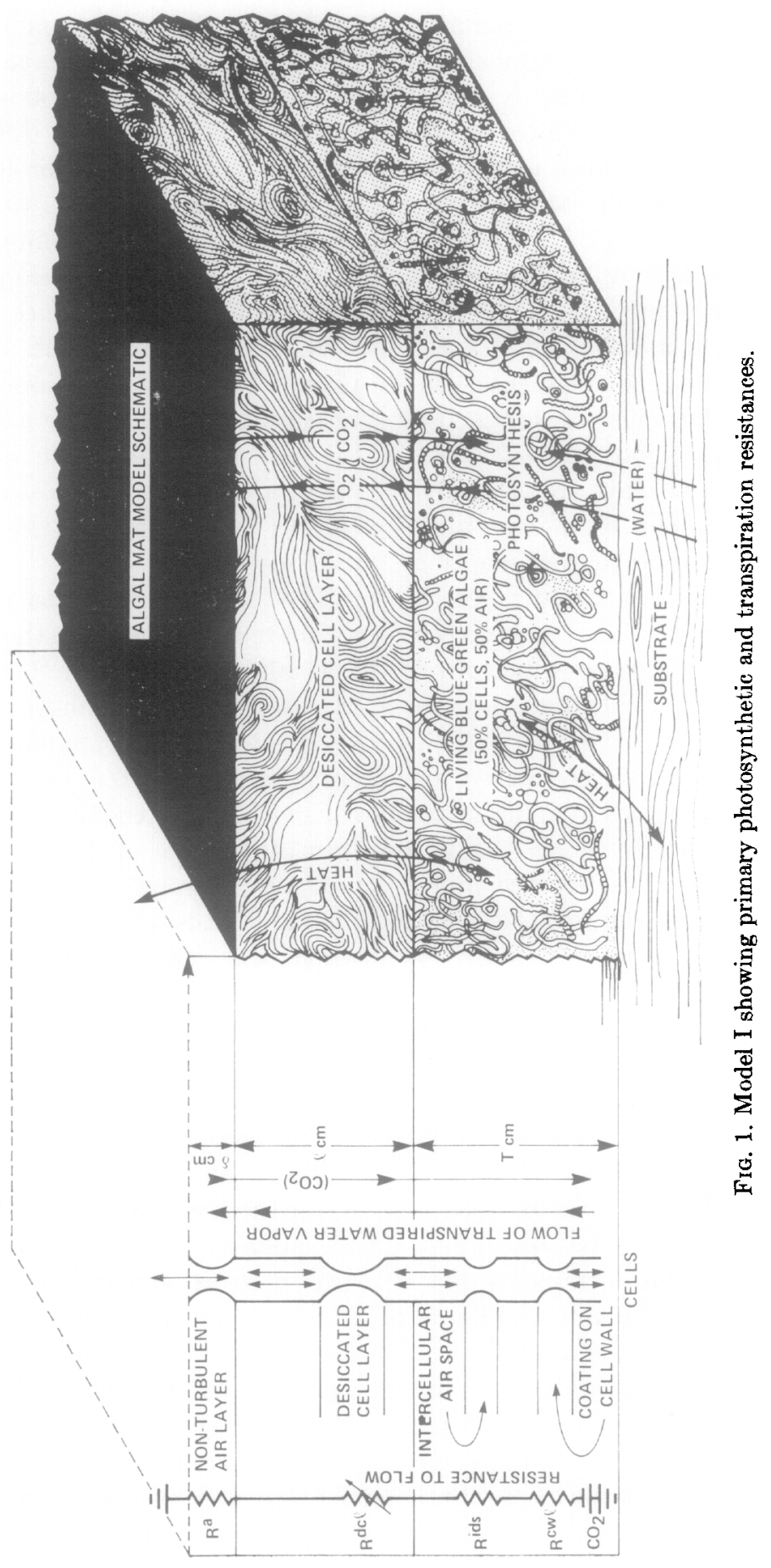


Viking 1 measured a near-surface wind speed of about 4 to $10 \mathrm{~m} \mathrm{sec}^{-1}$ (Shorthill et al., 1976). We developed a radiation model and calculated the atmospheric infrared radiation to be $0.023 \mathrm{ly} \mathrm{min}^{-1}$. Although we included this infrared radiation in the model, it provides a negligible contribution in comparison to the other energy balance components. Model I, which is similar to a community of bluegreen algae, is shown in Fig. 1. The organisms are envisioned as existing in a thin layer of interdigitating filaments surrounded by a gelatinous covering, and residing at or just below the surface of the planet. Since algal mats are commonly cuticose in their upper segments, a desiccated layer is proposed to exist overlying the active cells. This desiccated layer, we suggest, may initially result from exposure of cells to rapid moisture loss which would be characteristic of the Martian environment. We chose this layer to have a thickness equal to that of the active cell layer. As shown later, such a desiccated matrix or similar barrier is necessary to prevent extreme water loss by the underlying cells. The thickness of the active cells is chosen as $500 \mu \mathrm{m}$, which by terrestrial standards is relatively thin; however, we assume the severe Martian environmental conditions will not permit luxuriant growth. The layer is in direct contact with the Martian surface (or immediate subsurface) and consists arbitrarily of $50 \%$ cells by volume, the remainder being water-saturated air.

The resistance of water transpiration is due to the cell walls, the intercellular air spaces, and the external nonturbulent air layer. In plant leaves, a waxy layer may be incorporated into the cell wall (Nobel, 1970). The resistance of xerophytes may reach $2 \mathrm{sec} \mathrm{cm}^{-1}$, the value we choose, and represents a high degree of drought adaptation. We calculated a value of $8.6 \times 10^{-4} \mathrm{sec} \mathrm{cm}^{-1}$ for the resistance of the intercellular air space which cor- responds to a layer thickness of $0.25 \mathrm{~mm}$, and a Martian water vapor diffusion coefficient of $29.2 \mathrm{sec} \mathrm{cm}^{-1}$. The resistance of the desiccated cell layer was varied in the model from 0 to $1000 \mathrm{sec} \mathrm{cm}^{-1}$.

The resistance to the diffusion of carbon dioxide and water vapor is approximately inversely proportional to the ratios of their diffusion coefficients. Although the resistance to $\mathrm{CO}_{2}$ diffusion should include the additional resistance from the cell wall, the plasmalemma, and the cytoplasm, their contributions to the overall resistance are small ; for example, a typical plasmalemma resistance is about $0.5 \mathrm{sec}$ $\mathrm{cm}^{-1}$, a cytoplasmic resistance about 0.005 sec $\mathrm{cm}^{-1}$, and that of the cell wall about $0.01 \mathrm{sec} \mathrm{cm}^{-1}$.

The maximum photosynthetic rate is estimated to involve the production of $8 \times 10^{-7}$ mole $\mathrm{O}_{2} \mathrm{~cm}^{-2} \mathrm{hr}^{-1}$ (Kratz and Myers, 1955). We also assume that $1 \mathrm{~g}$ of dry weight represents $800 \mathrm{~cm}^{2}$ of coverage of a mat $0.5 \mathrm{~mm}$ thick. The $\mathrm{Mi}$ chaelis-Menten coefficients were estimated from the data of the above authors as $6 \times 10^{-3} \mathrm{ly} \mathrm{min}^{-1}$ for $k_{2}$ and $4 \times 10^{-6} \mathrm{M}$ for $k_{1}$. Photosynthesis is assumed to cease when the colony temperature drops to $273^{\circ} \mathrm{K}$ or when the water loss of the cells decreases by $10 \%$. At this time, the cells are assumed to be in a quasi-dormant state of metabolic shutdown.

The second model (Fig. 2) differs primarily from Model I in that Model II has a thicker colony and the parameter $k_{1}$ is smaller and thus the photosynthesis rate is more strongly dependent than in Model I on the solar radiation. In addition, the rate of photosynthesis depends explicitly on the degree of water saturation as opposed to Model I in which photosynthesis was assumed to terminate when the cellular water content dropped to $10 \%$.

The numerical values chosen for the parameters in Model II correspond to those for a lichen. This model is a rectangular parallelpiped of square upper 





surface with an edge length of $1 \mathrm{~cm}$. The thickness of this segment $T$ can vary from 0.5 to $3 \mathrm{~mm}$, and includes the colony of organisms in a homogeneous matrix (25\% cells by volume) and a very thin cuticose protective layer over the top surface.

We estimated the photosynthetic parameters from data of Lange (1969) for some Negev desert species of lichen; $k_{2}$ is $1.25 \mathrm{ly} \mathrm{min}^{-1}$ and the maximum photosynthetic rate $P_{m}$ is $1.4 \times 10^{-6}$ mole $\mathrm{CO}_{2}$ $\mathrm{cm}^{-2} \mathrm{hr}^{-1}$. The value for $k_{1}$ remains the same as in Model I, i.e., $4 \times 10^{-6} M$. From data of Lange (1969), the relationship of lichen photosynthesis to the water content of the lichen thallus roughly follows firstorder and then zero-order kinetics. This process has been included in (3) as explained previously. Since $100 \%$ saturation falls within the middle of the observed maximum range, this value was selected as the maximum possible water content. The data further indicate that the minimum water saturation which allows photosynthesis is $20 \%$. In addition, the minimum temperature at which the colony is photosynthetically active is set at $260^{\circ} \mathrm{K}$; this cutoff is reasonable in the light of pub- lished observations (e.g., Lange and Kappen, 1972).

The total effective resistance to water vapor diffusion has been estimated empirically from the data of Stocker (1927); we find a resistance of $2.8 \mathrm{sec} \mathrm{cm}^{-1}$ under the assumption that $1 \mathrm{~g}$ of dry weight corresponds to $25 \mathrm{~cm}^{2}$ of surface coverage. As before, the resistance to $\mathrm{CO}_{2}$ diffusion can be found from the resistance to water vapor.

\section{RESULTS}

\section{Model I}

For all conditions considered, i.e., an equatorial equinox, wind speeds varying from 1 to $1000 \mathrm{~cm} \mathrm{sec}-1$, colony thickness of $0.5 \mathrm{~mm}$, and a desiccated cell layer with resistance varying from 0 to 1000 $\mathrm{cm} \mathrm{sec}{ }^{-1}$, the colony temperature is within $1^{\circ}$ of the surface temperature even though the air temperature near the ground is some $65^{\circ} \mathrm{K}$ less than at the surface. Thus, for thin colonies a knowledge of the diurnal surface temperatures can be used to predict the time the colony will be above the freezing point of free water.

The variation in water loss during the day is shown in Fig. 3. The numbers in

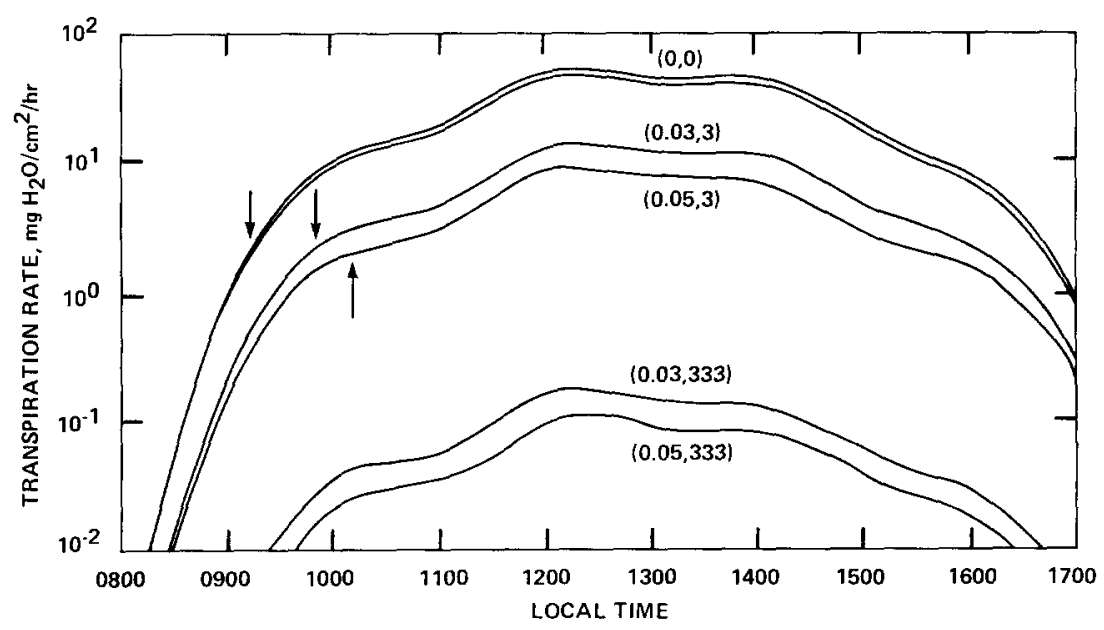

FIG. 3. Transpiration rates for Model I. Solid arrows refer to times at which $10 \%$ water loss occurs. Numbers in parentheses refer to the thickness of the colony (in centimeters) and the resistivity (per second), respectively. 


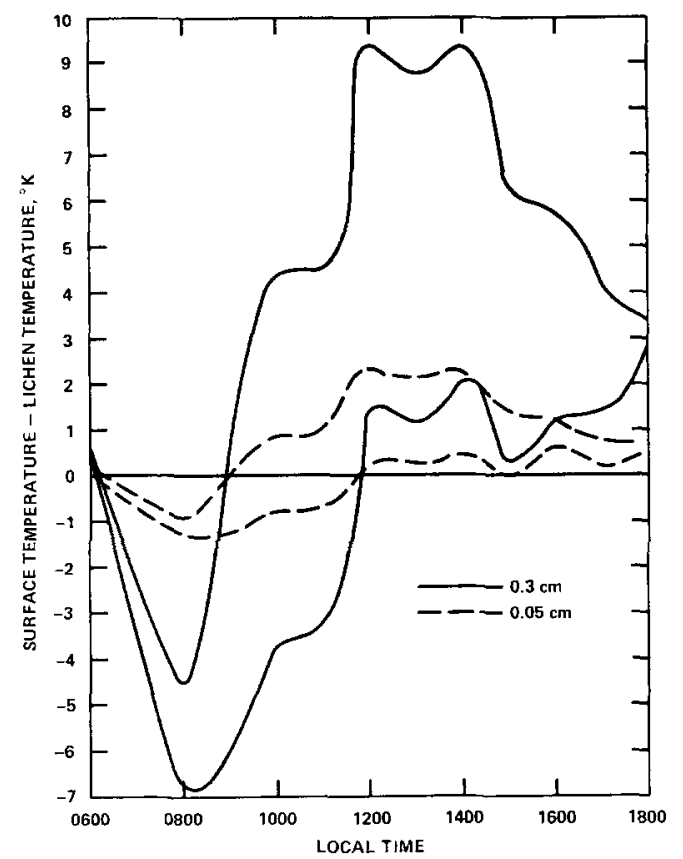

FIG, 4. Variation of colony temperature from surface temperature in Model II for thickness of 0.3 and $0.05 \mathrm{~cm}$. The upper curve in each case corresponds to a wind speed of $1000 \mathrm{~cm} \mathrm{sec}^{-1}$, while the lower curve represents a wind speed of $1 \mathrm{~cm} \mathrm{sec}^{-1}$.

parentheses refer to the desiccated layer, the first being the thickness of the layer and the second the resistivity; the resistance of the layer is the product of these two numbers. The solid arrows on the uppermost three curves are the times for which the organism has reached a $10 \%$ water loss, the total amount of water in the organism being $25 \mathrm{mg} \mathrm{cm}^{-2}$. For the lowermost two curves, which represent the largest resistivity, the water loss does not reach $10 \%$ during the day, but is $2.4 \%$ for a $0.03-\mathrm{cm}$ mat, and $1.5 \%$ for the other. In all cases, the colony is annually above $273^{\circ} \mathrm{K}$ from 1000 to $1600 \mathrm{hr}$ local time. We assume photosynthesis can only occur when an organism temperature of $273^{\circ} \mathrm{K}$ has been reached, and in addition that photosynthesis will cease when the water loss is reduced by $10 \%$. Notice that if the resistance to water loss is less than 0.15 (uppermost three curves), then photosynthesis will not occur since the organism is desiccated by sublimation before the freezing point is reached. If no desiccated layer is present, water loss will be complete, and the colony cannot survive. A desiccated layer with resistance greater than about 10 appears necessary for survival of the organisms.

Note that the wind speed is not a major factor in water loss. The diurnal variation in water loss, primarily controlled by surface temperature, is several orders of magnitude, while a change in wind speed from 1 to $1000 \mathrm{~cm} \mathrm{sec}^{-1}$ is only detectable in Fig. 3 when no desiccated layer is present.

The rate of photosynthesis is essentially constant throughout the day, the reason being that the rate coefficient for radiation $\left(k_{2}\right)$ is very small $\left(6 \times 10^{-3}\right.$ ly $\left.\mathrm{min}^{-1}\right)$ so that even at 0700 local time, when the solar radiation is $0.22 \mathrm{ly} / \mathrm{min}$ the ratio $6 \times 10^{-3} / 0.2 \ll 1$, and the rate of photosynthesis is independent of light intensity [see Eq. (3)]. Desiccated layers with resistance greater than about 10 yield about $10^{-6}$ mole $\mathrm{O}_{2} \mathrm{~cm}^{-2} \mathrm{day}^{-1}$.

\section{Model II}

Diurnal departures in the colony temperature from surface temperatures for different thicknesses and wind speeds are shown in Fig. 4. In the early morning, colony temperatures are higher than surface temperatures, while in the afternoon, the reverse is true - a consequence of the larger evaporative cooling associated with the higher temperatures. As the wind speed increases, the heat loss to the atmosphere becomes larger, and the colony temperature decreases. Also, the thicker the colony, the more its temperature decreases. The thicker the colony, the more its temperature differs from that of the surface since conduction has a smaller effect. 


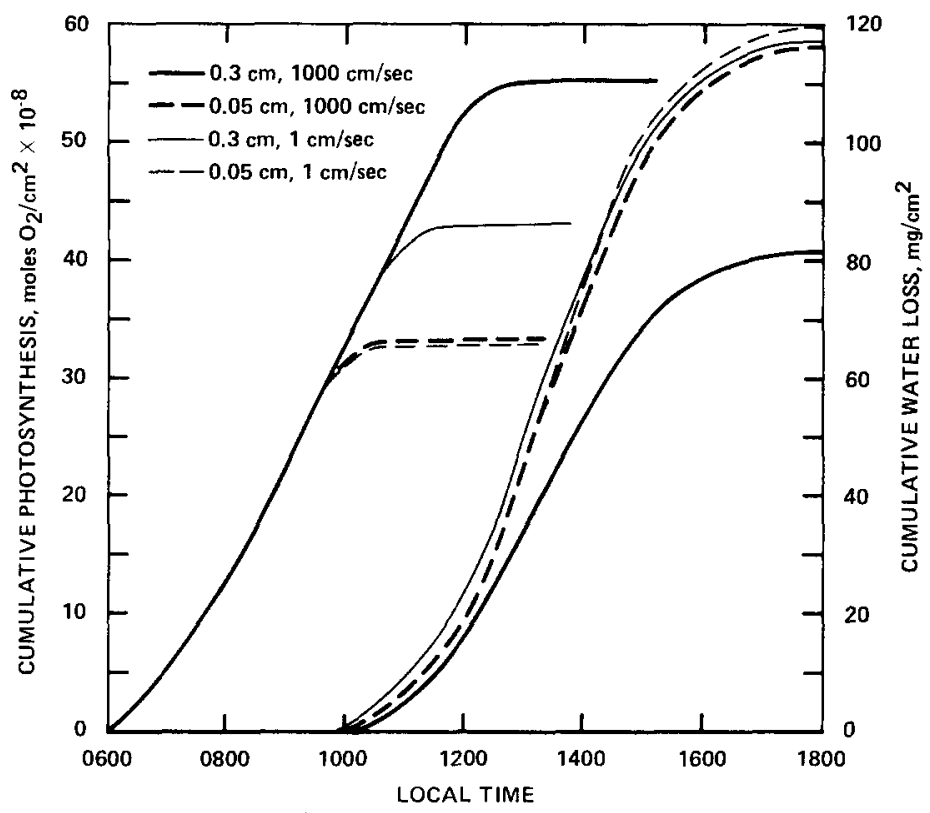

FIG. 5. Cumulative water loss (right) and photosynthetic rates for Model II (left) for different colony thicknesses and wind speeds.

For the sheltered conditions (Fig. 5), i.e., with a wind speed of $1 \mathrm{~cm} \mathrm{sec}-1$, the water loss is large and is not strongly dependent on the colony thickness. Note that for a given wind speed, the greater the thickness of the colony, the smaller the water loss. This is a result of the lower colony temperature associated with its larger thickness. Also, for a given thickness, the water loss decreases with increasing wind speed. This is due to the lowered organism temperature which in turn lowers the saturation water vapor pressure and thus the water loss. This process is more significant than the decrease in air boundary-layer thickness which decreases the resistance to water loss.

The maximum rate of photosynthesis (Fig. 5) is only about one-tenth that of Model I, i.e., about $10^{-7}$ mole $\mathrm{O}_{2} \mathrm{~cm}^{-2}$ $\mathrm{day}^{-1}$. This is because the larger rate coefficient, $k_{2}$, produces large diurnal variation in the photosynthetic rate. Photosynthetic rate has a reverse relationship to wind speed and colony thickness com- pared to transpiration rate, i.e., as the wind speed and/or thickness increase, the transpiration rate decreases, permitting a corresponding increase in photosynthesis. This comes about because an increase in wind speed causes a smaller boundarylayer thickness and thus a small $r^{\prime}$. Also, a larger wind speed means a lower rate of water loss and a larger percentage water saturation $S$. Equation (3) suggests that both parameters therefore tend to increase the photosynthetic rate. In Fig. 5 the cumulative photosynthesis is also plotted if water loss and temperature were not limiting factors. However, if the limiting temperature and the water loss are $260^{\circ} \mathrm{K}$ and $80 \%$, respectively, then photosynthesis could occur for only about $3 \mathrm{hr} /$ day. The colony would reach this temperature in the morning at about 0930, but water loss would terminate the process about $3 \mathrm{hr}$ later.

\section{CONCLUSIONS}

A mathematical model has been developed that relates a hypothetical colony 
of Martian photosynthetic organisms to the surface temperature, solar radiation, and temperature and winds in the Martian atmosphere.

For colonies less than a few millimeters thick, the temperature will be controlled by the surface temperature even though the air temperature may be some $70^{\circ}$ below freezing and surface winds reach $10 \mathrm{~m} \mathrm{sec}^{-1}$. Transpiration is appreciable because of the lack of water vapor in the atmosphere. The loss of water is actually retarded at high wind speeds, since the lowered organism temperature reduces the water vapor pressure in the organism. This effect is more significant than the promotion of water loss by the smaller air boundary layer which is generated with increasing wind speed. Typical photosynthetic rates for colonies near the equator would be about $10^{-6}$ to $10^{-7}$ mole $\mathrm{O}_{2} \mathrm{~cm}^{-2}$ day $^{-1}$.

Variations in Martian orbital parameters change the seasonal and latitudinal distributions of the incident radiation appreciably, which in turn may cause climatic variations with time scales of about 25,000 years (see, e.g., Sagan, 1971; Ward et al., 1974). It is interesting to speculate that during a warmer climatic period, when the polar ice could have been present as liquid water, the developing Martian organisms if indeed they did exist may not have been drastically different from primitive terrestrial organisms. A primary difference could have been a sheath or cortex over the active cells to provide some shielding from ultraviolet radiation. Such a layer need not be very thick according to the models used in this study.

Primary uncertainties in the model calculations concern the parameters for the colony of organisms. Experimental studies that subject a colony of photosynthetic organisms to anaerobic conditions simultaneously with continued low-level ultraviolet radiation are not available. Also, resistance parameters are only very approximate. Thus, there is a need for ad- ditional experimental studies before more sophisticated models are justified.

\section{ACKNOWLEDGMENTS}

We would like to acknowledge a number of enjoyable and fruitful discussions with Dr. Mel Averner. The majority of this work was done by the authors as part of a special program originated by R. D. MacElroy during the summer of 1975 . This program was devoted to a study of the habitability of Mars [NASA SP-414, "On the Habitability of Mars: An Approach to Planetary Ecosynthesis" (M. M. Averner and R. D. MacElroy, Eds.)]. A portion of this work was completed under contract A17362 B (NASA).

\section{REFERENCES}

Cameron, R. E. (1963): Morphology of representative blue-green algae. Ann. N.Y. Acad. Sci. $108,412-420$.

Gates, D. M. (1968). Toward understanding ecosystems. Advan. Ecological Res. 5, 1-35.

Givrasch, P. J., and Goody, R. (1968). A study of the thermal and dynamical structure of the Martian lower atmosphere. Planet. Space Sci. $16,615-646$.

Hess, S. L., Henry, R. M., Leovy, C. B., Ryan, J. A., Tillman, J. E., Chamberlain, T. E., Cole, H. L., Dutton, R. G., Greene, G. C., Srmon, W. E., and Mitchell, J. L. (1976). Mars climatology from Viking I after 20 Sols. Science 194, 78-80.

KAPPen, L. (1973). Response to extreme environments. In The Lichens (V. Ahmadjian and M. E. Hale, Eds.), pp. 311-380. Academic Press, New York.

Kratz, W. A., and Myers, J. (1955). Photosynthesis and respiration of three blue-green algae. Plant Physiol. 30, 275-280.

LANGE, O. L. (1969). Experimentelle ökologische Lntersuchungen an Flechten der Negev-Wüste, I. Flora 158, 324-359.

Lange, O. L., and Kappen, L. (1972). Photosynthesis of lichens from Antarctica. Antarctica Res. Ser. 20, 83-95.

Levine, J. S. (1976). A new estimate of volatile outgassing on Mars. Icarus 28, 165-169.

Lund, J. W. G. (1962), Soil algae. In Physiology and Biochemistry of Algae (R. A. Lewin, Ed.), pp. 759-770. Academic Press, New York.

Metz, W. L. (1976). Viking (I): End of first phase of 70's space spectacular. Science 194, $819-820$.

Monteith, J. L. (1973). Principles of Environmental Physics. American Elsevier, New York. 
NoBEL, P. S. (1970). Introduction to Biophysical Plant Physiology, pp. 314-338. Freeman, San Francisco.

RaO, D. N., and Le Blanc, F. (1966). Effects of sulfur dioxide on the lichen algae, with special reference to chlorophyll. Bryologist 69, 69-75.

SAGAN, C. (1971). The long winter model of Martian biology: A speculation. Icarus 15, 511-514.

Sagan, C., and Pollack, J. B. (1974). Differential transmission of sunlight on Mars. Icarus 21, 490-495.

Shorthill, R. W., Moore, H. J., Scotr, R. F., Hutton, R. E., Liebes, S., And Spitzer, C. R. (1976). The soil of Mars. Science 194, 91-97.

Sieger, S. M., ANd Daly, O. (1968). Responses of Cladonia rangiferina to experimental stress factors. Bot. Gaz. 129, 339-345.

STOcker, O. (1927). Physiologische und Ökologische Untersuchungen an Laub- und Strauchflechten; ein Beitrag zur experimentellen Ökologie und Geographie der Flechten. Flora 121, 334-415.

Toulmin, P. T., Clark, B. C., Baird, A. K., KeIl, K., and Rose, H. J., JR. (1976). Preliminary results from the Viking X-ray fluorescence experiment: The first sample from the Chryse Planitia, Mars. Science 194, 81-83.

WARD, W. R. (1973). Large scale variations in the obliquity of Mars. Science 181, 260-262.

Ward, W. R., Murray, B. C., and Malin, M. C. (1974). Climatic variations on Mars. 2. J. Geophys. Res. 79, 3387-3395. 